\title{
Review \\ Key Elements of Mobility Apps for Improving Urban Travel Patterns: A Literature Review
}

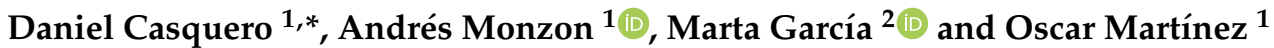 \\ 1 Transport Research Centre-TRANSyT, Universidad Politécnica de Madrid, 28040 Madrid, Spain; \\ andres.monzon@upm.es (A.M.); oscar.martinez@upm.es (O.M.) \\ 2 Department of Construction, School of Technology, University of Extremadura, 10003 Caceres, Spain; \\ martagg@unex.es \\ * Correspondence: daniel.casquero@upm.es
}

check for updates

Citation: Casquero, D.; Monzon, A.; García, M.; Martínez, O. Key Elements of Mobility Apps for Improving Urban Travel Patterns: A Literature Review. Future Transp. 2022, 2, 1-23. https://doi.org/ 10.3390/futuretransp2010001 Academic Editor: António P. Antunes Received: 30 September 2021 Accepted: 27 December 2021 Published: 4 January 2022

Publisher's Note: MDPI stays neutral with regard to jurisdictional claims in published maps and institutional affiliations.

Copyright: (C) 2022 by the authors. Licensee MDPI, Basel, Switzerland. This article is an open access article distributed under the terms and conditions of the Creative Commons Attribution (CC BY) license (https:// creativecommons.org/licenses/by/ $4.0 /)$.

\begin{abstract}
In recent decades cities have applied a number of policy measures aimed at reducing car use and increasing public transportation (PT) patronage. Persuasive strategies to change mobility behavior present notable limitations in economic and logistical terms and have only minor impacts. The smartphone has emerged as a promising tool to overcome these challenges, as it can host persuasion strategies through mobility apps. Simultaneously, Mobility-as-a-Service (MaaS) schemes could open up new possibilities for addressing both sustainability goals and the needs of urban travelers. This paper carries out a literature review to identify the key elements of mobility apps that foster more sustainable travelers' choices. The findings show that some persuasive strategies such as eco-feedback, rewards or social challenges are effective because they are well received by users. From the users' point of view, the perceived barriers (e.g., usability, privacy) relate negatively to app adoption, and it is considered useful to include functional needs such as real-time information (e.g., to avoid congestion), cost savings (e.g., customized multimodal packages), comfort (e.g., crowding on public transport) or health (e.g., calories burned). We have found that a proper design of multimodal travel packages based on (i) financial incentives and (ii) environmental awareness, could help increase public transport patronage and reduce private car use.
\end{abstract}

Keywords: mobility apps; travel behavior; transfer car trips to PT; persuasive technology; Information and Communication Technology (ICT)

\section{Introduction}

Many cities have been planned or transformed to allow massive car use, and major efforts are needed to reverse this situation. The current challenge is therefore to convince travelers to choose more sustainable modes of travel. The measures implemented to meet this challenge have generally been classified as "hard" and "soft". Hard measures, involving changes to transport infrastructures with high associated costs for public administrations, are sometimes controversial and are unfeasible for politicians [1]. For this reason, public administrations have started to take an interest in soft measures, which try to persuade and make sustainable mobility more attractive. Among the soft measures, travel behavior change programs (TBCP) have become popular, demonstrating their potential to reduce car use [2]. However, their effects on participants are somewhat limited and they are difficult to apply to large population groups [3].

ICT has changed the way travelers move around cities, as smartphone technology provides users with high-value information. The arrival of smartphones may dramatically help change travel patterns [1] and enhance the effects of TBCP interventions. In the last decade, some TBCP programs have started to be run through smartphones [2,3], and are known as technology-based interventions. In this case, travel apps incorporate persuasive elements to encourage users to adopt sustainable modes of transportation. 
The literature has paid increasing attention to the introduction of elements in mobility apps [4-6] to foster positive changes in travel behavior. The main objective of these "appbased persuasive technologies" is to foster environmental sustainability, promote healthier trips and contribute to livable cities. In parallel, since the launch of UbiGo-the first MaaS platform-travelers' needs have received more attention. The alignment of MaaS with sustainability goals is a clear dimension for its adoption [7]. There is therefore a gap to be filled in the scientific literature, consisting of compiling all the findings from different studies on the travel elements and characteristics that persuade people to choose more sustainable transport modes. The lessons learned from MaaS experiments are always user centered [8]. An urban travel app will be more attractive if it provides synergic interactions between sustainable mobility options and individual benefits such as money or time savings, increased access to different modes, ease of use, etc.

Figure 1 shows a mobility app designed with a user-centered approach (smartphone on the left) that incorporates persuasive strategies that encourage sustainable mobility habits (on the right). In addition, the regulatory framework and business viability are key to the development of these apps [9].

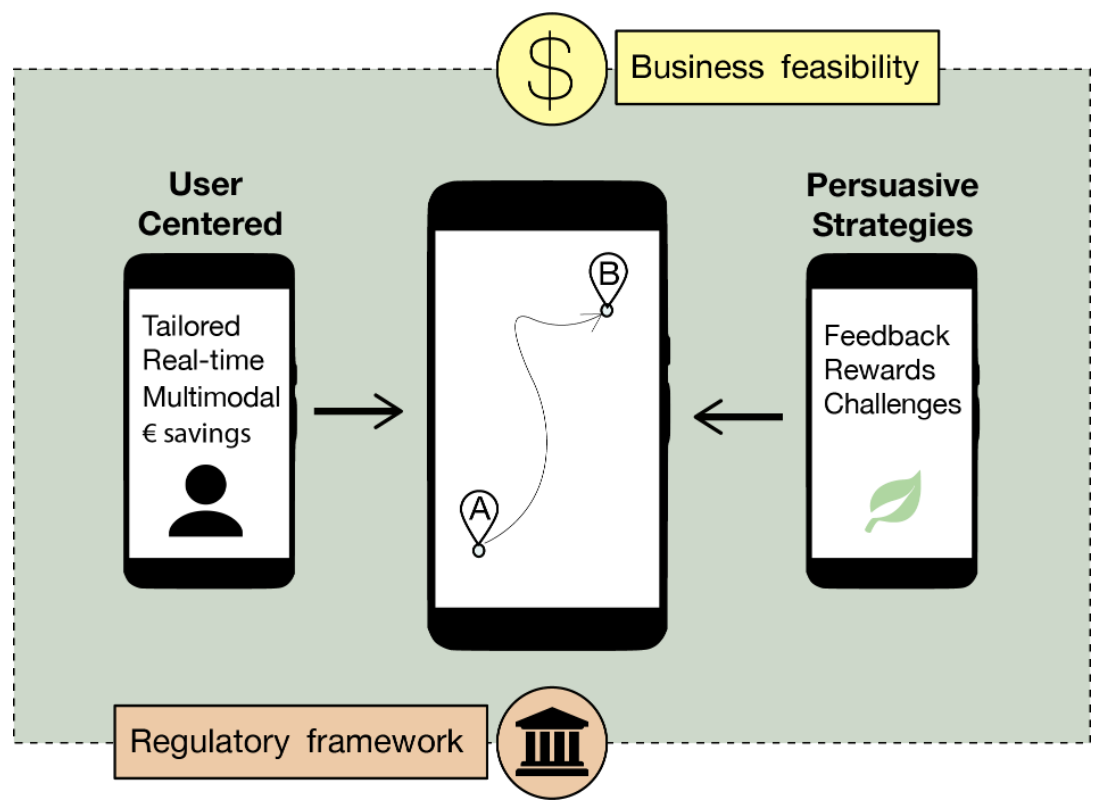

Figure 1. Mobility app design scheme.

Specifically, this review aims to summarize findings on the factors that encourage the use of urban travel apps from the traveler's perspective, and determine which elements in these apps encourage more environmentally friendly mobility. This review could be important for app developers, public bodies, and private stakeholders. Urban mobility researchers and developers will also find a way forward for the effective use of sustainability-oriented technologies.

After this introduction, the paper includes a methodology to identify the most important papers and case studies. The Section 3 then classifies and analyzes them according to the most relevant topics selected. Section 4 summarizes the main findings and key elements of travel apps for improving mobility decisions. Finally, the Section 5 offers some policy recommendations and suggests further research and analysis.

\section{Methodology}

This section explains the methodology applied to conduct the literature review, including the databases that were searched, the keywords used to search the papers, the inclusion and exclusion criteria, the process to ensure that the search for papers is well focused using 
the VOSviewer software [10], and the framework for comparing different dimensions from the most relevant papers selected.

\subsection{Databases and Exclusion/Inclusion Criteria}

Three databases were used in the search for scientific papers: Web of Science (WoS), as all its publications have a JCR impact index, and the search was then expanded to Scopus and Google Scholar. In both Scopus and Google Scholar only journals with a JCR index were taken into consideration.

The search logic was the same in the three databases. The goal was to gather and analyze scientific research on two topics: (i) the elements that apps must include to persuade users to make more sustainable trips; and (ii) what makes an app appealing to travelers. The word string chosen for the search was: "smartphone" AND "travel information".

Only scientific works in English were considered and the time range of the publications is from 2014 to July 2021. Figure 2 shows that the major upsurge in the number of papers on smartphones occurred in 2014, which may indicate that the topic became relevant. The following scientific fields were searched, taking into account the differences between WoS and Scopus: Transportation, Engineering, Urban Studies, Geography, Social Sciences, Psychology, Environment, Computer Science, Interdisciplinary or Multidisciplinary scientific areas, Business and Economics.

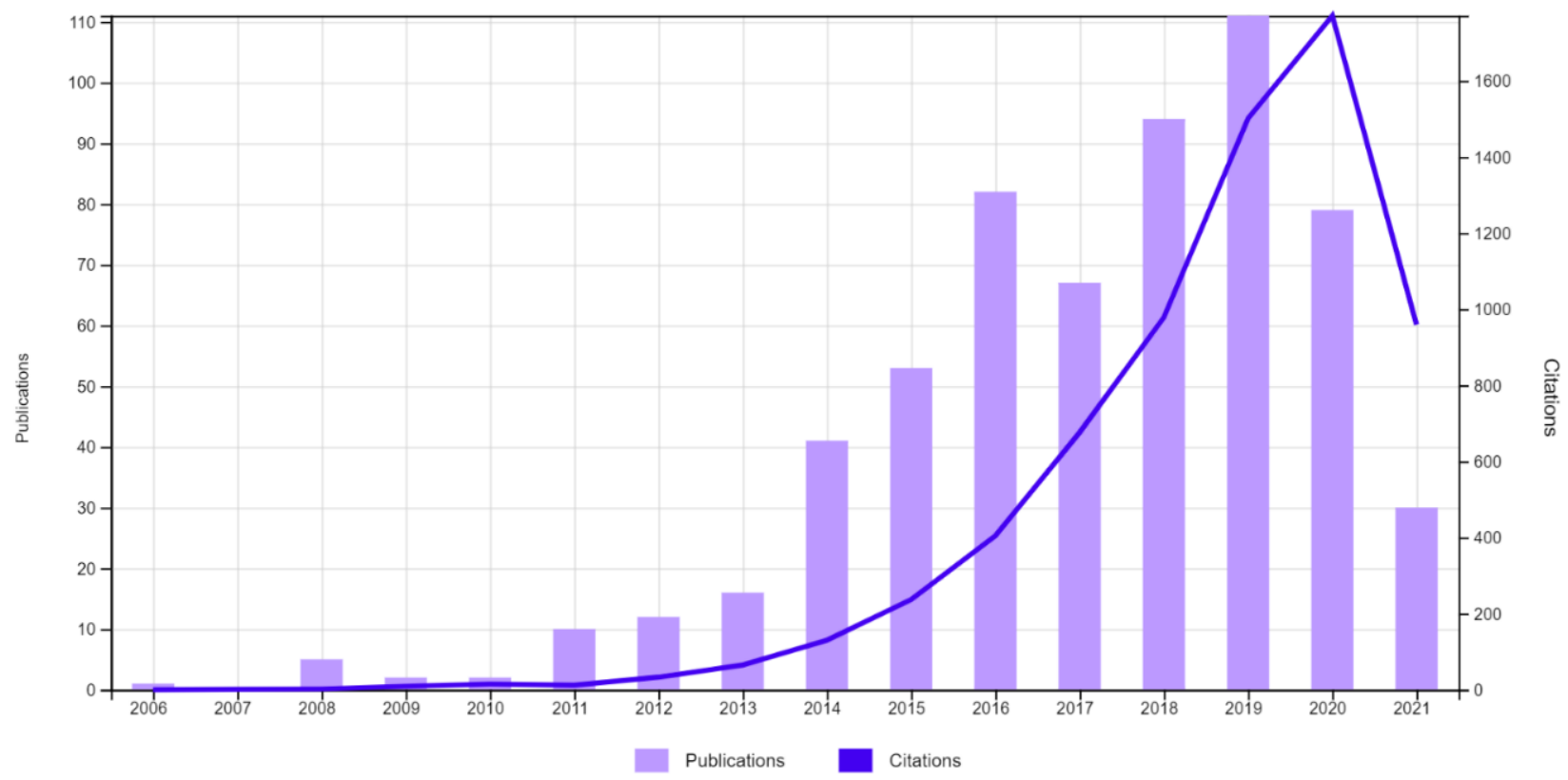

Figure 2. Times cited and publications over time. Source: Web of Science.

The search in Google Scholar was simpler because it does not allow as many exclusion/inclusion criteria as WoS or Scopus. Only papers containing the words "smartphone" and "travel information" and which were published between 2014 and 2021 were restricted. The search criterion "by relevance" was used according to Google Scholar (https: / / scholar.google.com/intl/en/scholar/about.html (accessed on 23 July 2021)), which considers the journal of publication, the authors and the number of citations and the date on which they were cited. The search yielded "about 4050 results", but a limit was established so only the first 500 were considered.

\subsection{Bibliographic Analysis}

VOSviewer is a bibliometric and network analysis software [11] that was used to ensure that the search was focused on the specific object of the research, and to graphically 
visualize the network of all the key concepts in the list of scientific articles searched, and how they relate to each other.

A first VOSviewer graph was generated after the first search, but it contained clusters with concepts unrelated to the subject of this study. The search was performed again filtering those terms and a VOSviewer graph was generated again. The graph is shown in three different ways, in Figures 3-5, for ease of interpretation. Each figure highlights a relevant keyword to the topic of this study and its network of relationships to other keywords. Figure 3 highlights "location", Figure 4 "app" and, Figure 5 "travel behavior".

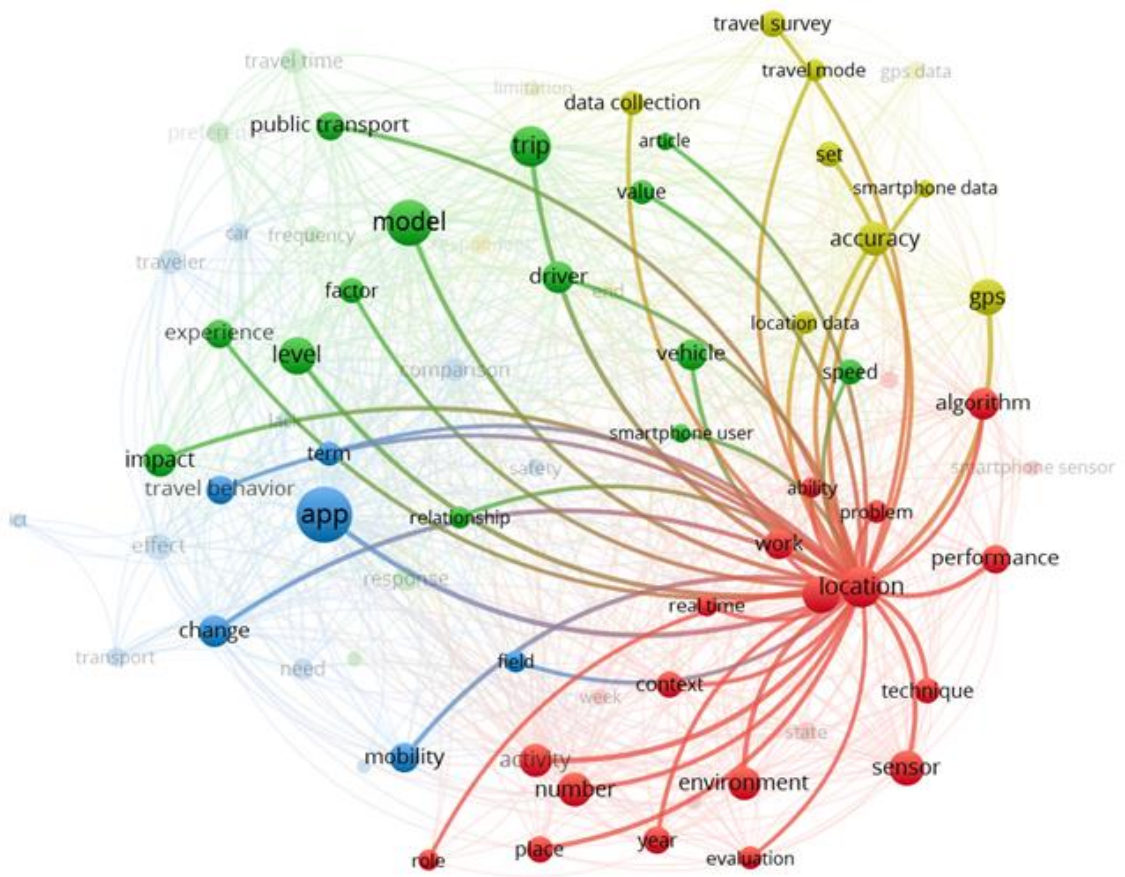

Figure 3. Co-occurrences of "location". Source: VOSviewer.

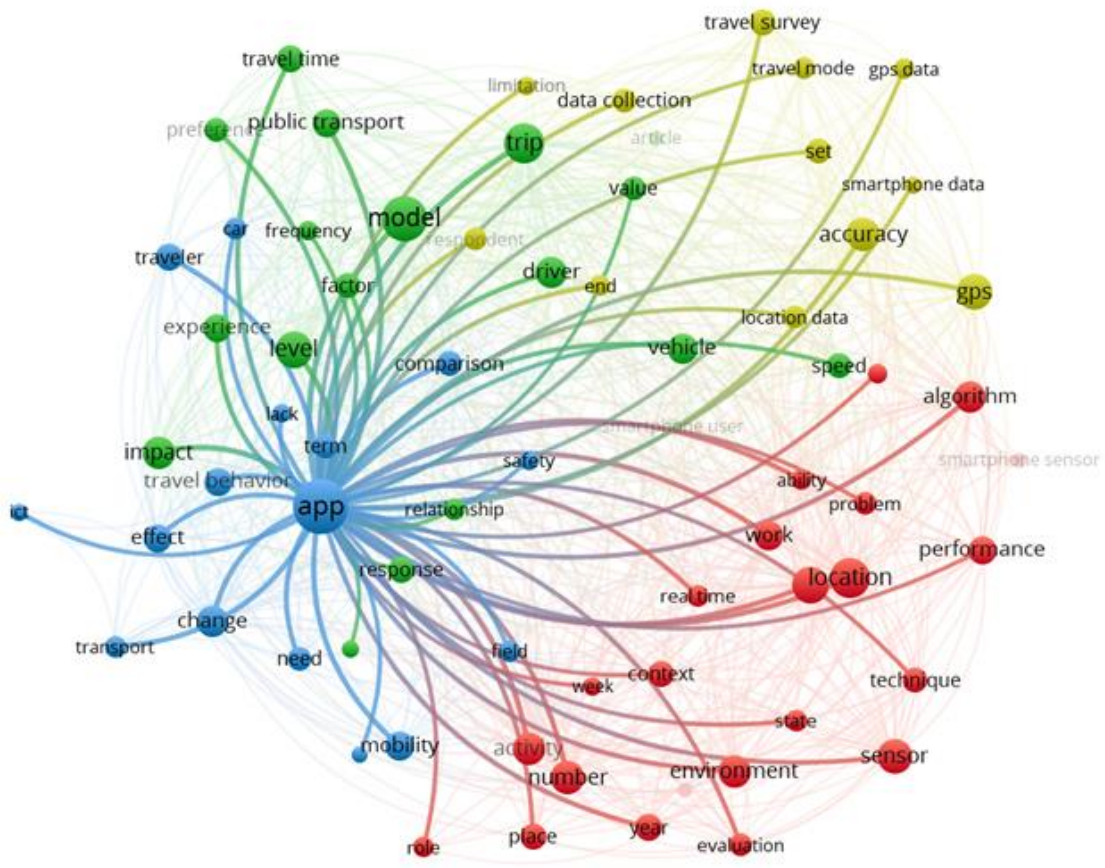

Figure 4. Co-occurrences of "app". Source: VOSviewer. 


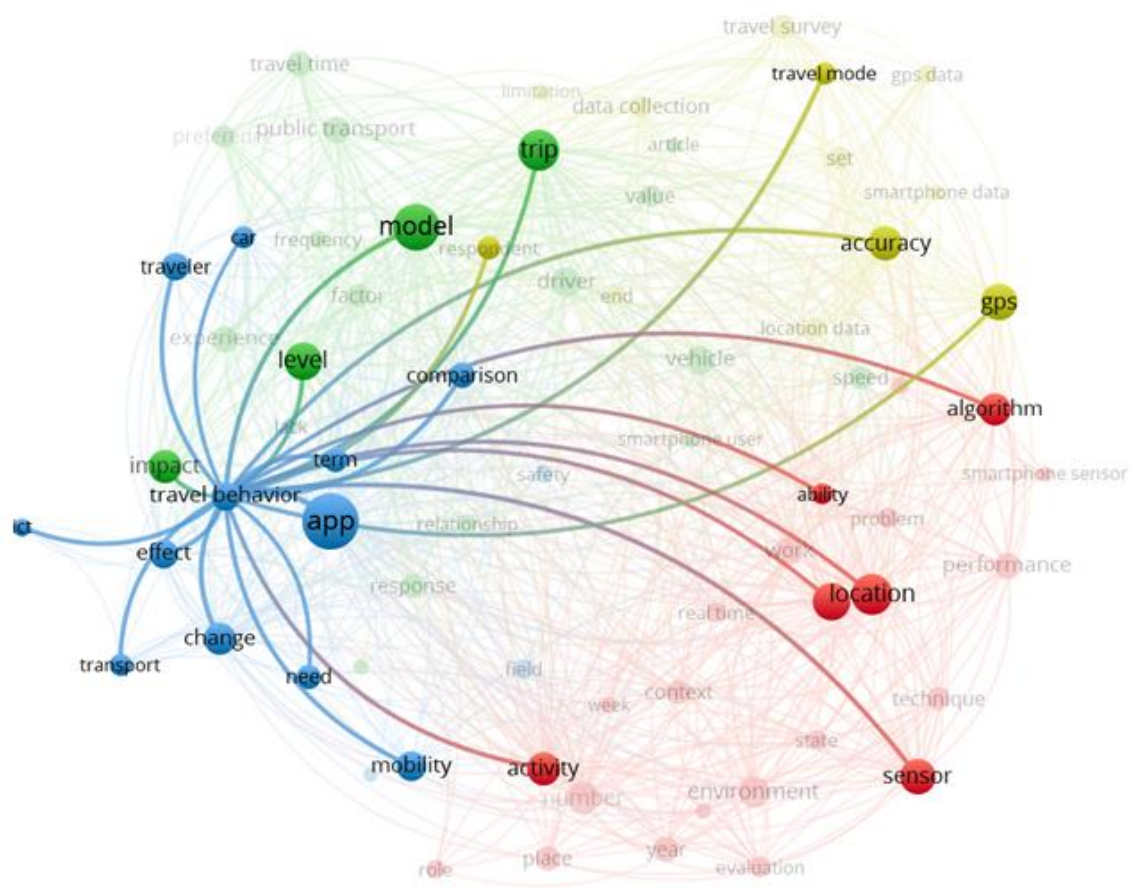

Figure 5. Co-occurrences of "travel behavior". Source: VOSviewer.

The size of each keyword in the VOSviewer graphs is determined by the number of co-occurrences. A keyword has one co-occurrence when it appears in one scientific article in which another keyword also appears. If a keyword has a high number of co-occurrences, it implies that it coincides with a high number of keywords in the articles.

Looking at Figure 3, "location" is connected to "year", "place" or "context", which refers to the importance of the temporal and geographical context. In the case of a mobility app, the geographical context in which it will be used is decisive. It is also related to "sensor", "GPS", "real-time" and "algorithm", which allude to the tracking of travel behavior (route, travel mode, speed, etc.).

Figure 4 shows the network for "app". In contrast to the terms "location", and particularly "travel behavior", the number of relationships between "app" and other keywords is visibly higher, as all four clusters group keywords related to "app". This confirms the importance of "app" in the search.

Figure 5 highlights the connections between "travel behavior" and other keywords in the search, all of which are closely related to this research; for example: "mobility", "car", "travel mode", "app", "ICT", "change", "effect" and "impact".

A wide variety of connections can be established between "location", "app" and "travel behavior" from a mobility perspective. For example, the user's location when traveling, the use of mobility apps during travel, and the influence it has on their travel behavior are all key to this research. This VOSviewer graph therefore contains terms and relationships that are essential to the object of the study. The search for scientific articles can be seen to be well targeted.

\subsection{Selected Studies}

The WoS search yielded 338 scientific articles, Scopus 416 articles and from Google Scholar we used just the first 500 articles that it yielded. A significant number of these were found in all three databases, which, after filtering, finally yielded a total of 413 different scientific publications.

After the first VOSviewer graph, the search was repeated removing the unrelated terms to the subject of this study, and a total of 116 scientific papers were excluded. A 
second VOSviewer graph was useful to check that the search was well targeted. Finally, 297 publications were considered.

Of the 297 articles selected, only those that were empirical scientific articles (28) or literature reviews (7) were revised. Empirical articles include: (i) 15 studies that provide evidence on the performance of an existing mobility app, or pilot apps and, (ii) 13 studies that conducted surveys or interviews that provide the opinions of users of existing apps or potential users of pilot apps. Empirical studies provided real or close-to-reality evidence and literature reviews served as a reference to advance research and do not overlap.

During the study of the selected papers, it was decided to expand the specific bibliography for the findings on urban travel apps (Section 3.1), using a snowballing approach (forward). Specifically, five more papers were considered, which were cited in the initially selected papers.

\section{Findings from the Literature Review}

In the following sections we analyze the main findings on two aspects: (i) user-centered mobility apps, and (ii) persuasive elements of mobility apps.

\subsection{User-Centered Mobility Apps}

This section analyzes the characteristics that travel apps must have to be attractive to users. Of the 297 papers searched, 23 papers were chosen for this section. After their study, five new references were added that were cited in these 23 papers (snowballing approach). Finally, this section was based on 28 papers: 22 empirical studies (Appendix A), four literature reviews and one on the importance of the user in the MaaS model. Most of the studies considered are related to the MaaS concept, given its user-centric perspective. Mobility as a service (MaaS) schemes emphasize the importance of satisfying user needs. However, these needs or preferences are clearly heterogeneous [12], so transport services should not be rigid but allow the user to choose their particular mode in the most flexible manner. From the user's point of view, this offers a broad set of options that can be combined in multiple ways; registration, planning, booking, payment and ticketing are highly valued by urban travelers [8].

\section{- Sociodemographics}

Recent studies show that sociodemographic factors are good predictors of the intention to adopt new mobility services such as app-based ride-hailing [13]. In terms of age, young people are highly inclined to use new forms of mobility such as sharing services, whereas they tend not to be considered by older adults, who are less open to technological innovations [14]. Senior travelers are increasingly taking environmental impact into account when choosing between different mobility options. DriveNow, a car-sharing service in Denmark, is seeing growth in the number of elderly people and women [15].

Young people express some concern in regard to car-sharing about the increased time costs of looking for parking at the destination [8], leading to problems in areas where parking is difficult.

Young (mainly tech-savvy) people are also a suitable target and are used to living with a range of technologies such as apps [16]. From an economic point of view, one of the reasons for reducing private car use is the financial burden it imposes [17]. The Park and Ride option is one way of reducing private car use. A recent study reveals that the probability of using this option decreases with income [18]. A study of users of the route-recommendation app Baidu (China) revealed that wealthier bus riders are less likely to use the app-based ride-hailing service [19], possibly because a significant portion of bus riders are older adults.

\section{- Real-time information}

One of the most important advantages offered by ICTs is the possibility of providing updated information at the moment it is demanded by the user, either through a website or an app. This has become a key requirement for transport system users [20] and must be 
both delivered in real time and also reliable. People today are highly sensitive having their time wasted, and as transportation is an activity that derives from other activities, travelers are less tolerant of wasted time.

In a recent study, participants who were mainly young people ( $<25$ years) emphasized the importance of network efficiency to avoid incidents, and of informing the user in real time of these incidents so as not to waste time. Specifically, travel duration, transport mode, itinerary, travel cost and service incidents are the areas of information most demanded by travelers [8].

A study carried out to test the travel app Metropia, which gives users real-time traffic information, enabled drivers to reduce their travel time by $5-10 \%$ [21]. The reduction in travel time, especially in waiting time, is recognized by several studies [22]. A recent experiment on travel time in a transit network compared two scenarios: in the first, the user did not use a smartphone (or any other form of real-time information) and took the first bus to leave the stop; while in the second, they used the smartphone to estimate the fastest route strategy, updated in real time. The travel time savings were over $15 \%$ when the smartphone was used (based on real-time information), mainly due to the reduction in waiting time at the origin stop [23]. Real-time information produces an upsurge in the number of public transport users; some authors claim that more than $30 \%$ of public transport app users increase their use of the bus [22].

Real-time reporting of incidents can modify the user's travel behavior (travel mode, route, deciding to delay departure time, etc.) [24]. This is confirmed by the results of a recent survey of bus passengers: $12 \%$ of the participants changed their route at least once due to incident notifications reported by other passengers [25].

Receiving information from passengers (e.g., reporting events) or providing users with a platform to exchange information in real time (e.g., an app to share information between users of the metro network) strengthens the management of the system from the perspective of the transport operator. Recent research on Denmark found that although the conditions of the transport system are well perceived by the user, there is significant interest (one third of users) in sharing information on the transit level of service (crowding, arrival times, delays, etc.). Following other authors, smart card data analysis does not serve as real-time information as it is retrospective [26]. The only source of real-time information is the active exchange of data by users, either in the form of permission to track phones, or messages to other users [27].

In regard to psychological aspects, a recent literature review on transit apps [22] extracted two key findings: (i) real-time information increases public transport users' perception of safety, especially in night waits and at "unsavory" stops, and among women. Knowing the estimated time of arrival in real time reduces the anxiety associated with the uncertainty of waiting; and (ii) more up-to-date information implies greater user satisfaction as it is more reliable.

\section{- Registration-planning-booking-payment method}

Planning trips well in advance brings clear economic and travel time benefits $[21,23]$. The registration and use of a single account (and ticket) to pay for the whole range of transport options available in the city promotes more efficient, seamless and multimodal mobility networks and increases their level of convenience [8].

However, subscribing to multimodal service packages allows users to travel more efficiently, as they think in advance about how they want to travel and decide on the most appropriate package; studies on this topic propose that this should be done on a monthly or quarterly basis. A large group of people may never have considered how they plan to travel, on a monthly basis. Subscription also brings the convenience of paying only once per subscription period [17]. Most research concludes that participants prefer subscription to a monthly service package than pay-as-you-go [8]. Recent studies reveal that users have heterogeneous mobility preferences, so it makes more sense to focus on ensuring the offer is as flexible as possible and allowing users to choose both the payment model and the services included in their bundle [12]. 
Users appear to choose based on predesigned packages [12]. Economic attractivenesseven in countries with high purchasing power such as Sweden and Australia [7,17] —and simplicity in terms of the inclusion of only a few transport modes [7] are also essential. Public transport is the preferred mode for inclusion [12], specifically "unlimited rides" [7,12]. A recent study has revealed that service subscription packages can be of great help to people with reduced mobility, especially if they can be customized [28].

\section{- Customization}

Personality factors have a major impact on people's mobile app adoption behavior, and this varies by app category [29]. Recent studies reveal current user demand for personalized assistance and mobility recommendations based on their profiles, needs and habits. The personalization of transport services, easily achieved through websites or travel apps, makes them more attractive and encourages loyalty and user engagement [8]. Digital platforms (apps or websites) can significantly help users who can no longer move around the city autonomously due to physical or intellectual disabilities. Interviews with the community transport sector (social care services) in Australia found an increase in the demand for more individualized services [28]. Travel apps can also help reduce car use for drivers by offering competitive alternatives, as time and comfort are known to be key for regular drivers [18].

\section{- Assistance}

Transportation systems in large cities are difficult for users to understand. Complementing the app's services with human customer service would be very attractive, particularly to elderly users. One of the main advantages of UbiGo was that it offered a mobility broker that acted as a mediator between service providers and users, facilitating the use of transport modes. Participants' satisfaction with UbiGo's response to their particular problems was very high (Likert scale, 6.2/7) [17].

\section{- Platform/community network}

Flexibility is a key aspect for encouraging people to take up the app. Flexibility can be understood as a concept associated with the ample possibility of customization by the user. A recent qualitative study [30], reported that users do not want to have only one mode available to them. In the same vein another study [24] argued that private car use provides a very high level of service to the user and proposed a 5-level scale of alternative transport services to the car. Level 5, the highest level, would be a similar service model to the one currently offered by the private car: convenient, door-to-door and with no cognitive cost.

Recent studies have found that it is important for the platform to be easy to use and to protect user information [17,31]. It should not be designed for technophiles but be intuitive for people with little command of the digital world.

One of the interesting aspects of the MaaS scheme is the value of cooperation or collaboration between users. It is proposed that the platform should encourage users to be active, provide information, and interact with other users and the transport operators. Social influence is key to travel behavior [12]. A potential user is significantly influenced by people in their closest people network subscribing to an MaaS package [12], and a digital network works better the more users it has (e.g., for rating transportation services) [32].

Companies are an appropriate place to create transportation service platforms for their employees. Employees know each other personally and may be more willing to use the platforms and share modes of transport, and they can be used to easily match schedules [20]. 
Impact Assessment of User-Centered Mobility Apps

Of the 22 studies, only nine correspond to real experiments or pilot tests. Table 1 shows a summary of those studies. They can be divided as follows:

1. By subject: six are related to MaaS experiences, while the other three are ride-hailing or car-sharing experiences.

2. By type of study: surveys exploring real experiences, pilot studies, and two MaaS experiences recently implemented in Taiwan: UMAJI and MenGo.

- $\quad$ Notes on the MaaS schemes in Table 1.

All MaaS platforms (UbiGo, Smile, UMAJI, MenGo, Touring, CMaaS and Tripi) have a booking tool and payment function, and only Smile does not have a monthly multimodal pass.

The UbiGo service was oriented to families and featured a mobility agent who aimed to personalize the offer to the user. Smile's customer service consisted of only a call center and an email address.

The area covered by UMAJI was exclusively the $40 \mathrm{~km}$ Taipei-Yilan corridor, where congestion needed to be reduced. It offered a monthly package for 43 USD that allowed the use of public bike, bus and metro.

MenGo offered different monthly multimodal packages depending on the travel modes selected, the number of trips per mode included in the subscription period and the total price. They were aimed at: (i) students aged 17 to 22; and (ii) the white-collar segment, The UMAJI and MenGo packages did not include new mobility services such as car/motorcycle sharing, ride-hailing or taxis.

The Touring app allowed booking and payment for different travel modes (car sharing, car rental, taxi, bus, streetcar, train, bike-sharing). Users were given a balance of between $€ 150$ and $€ 350$ to use only for the modes of transport and were asked to refrain from using the private car as much as possible.

Tripi offered four payment modes: pay-as-you-go or three different monthly multimodal passes (PT, Uber, taxi, car share, car rental). These have a clear green orientation, as one of them includes unlimited trips on public transport.

\section{- Changes in travel behavior}

All MaaS schemes produced some positive preliminary conclusions. All consider that larger tests and measurements by digital devices are needed [7]. In particular, one study [16] reports that significant reductions in car use will not come quickly. Of UbiGo users, $44 \%$ reported less car use, as did $21 \%$ of Smile users, also in the form of user reporting.

An evaluation was conducted in UMAJI and MenGo three months after the service became operational, showing a 3.2\% increase in public transport users in UMAJI (the single multimodal package included metro, bus and public bike). MenGo attracted a significant group of motorized travelers. In both cases a high percentage of initial users continued to use the service after three months. 
Table 1. Scientific studies on urban travel apps, real or experimental. Extracted from Appendix A.

\begin{tabular}{|c|c|c|c|c|}
\hline $\begin{array}{l}\text { App } \\
\text { [Ref.] }\end{array}$ & Location & Method & Description & Relevant Findings \\
\hline $\begin{array}{c}\text { UbiGo } \\
{[17]}\end{array}$ & $\begin{array}{l}\text { Gothenburg } \\
\text { (Sweden) }\end{array}$ & Pilot $[\mathrm{n}=195,6$ months $]$ & $\begin{array}{l}\text { Payment platform, multimodal monthly pass (per family). } \\
\text { Incentives for avoiding private car. Mobility agent. }\end{array}$ & $\begin{array}{l}\text { Users }(97 \%) \text { wanted to continue with the service. } \\
49 \% \text { perceived cost savings. } 44 \% \text { reported less car use. }\end{array}$ \\
\hline $\begin{array}{c}\text { Smile } \\
{[9]}\end{array}$ & $\begin{array}{l}\text { Vienna } \\
\text { (Austria) }\end{array}$ & Pilot $[n=200,1$ year $]$ & Multimodal info, payment platform, and customer service. & $\begin{array}{l}\text { 1. High rate of user satisfaction: } 75 \% \text { of users. } \\
\text { 2. Reduction in car-use: } 21 \% \text { of users reported. } \\
\text { 3. Public transport was used more often by } 48 \% \text { of users. }\end{array}$ \\
\hline UMAJI & $\begin{array}{l}\text { Taipei } \\
\text { (Taiwan) }\end{array}$ & In operation & $\begin{array}{l}\text { Multimodal info, payment platform, multimodal monthly pass } \\
\text { (bus, urban rail, public bike). }\end{array}$ & $\begin{array}{l}\text { After the first three months: PT ridership increased } 3.2 \% \text { and } 80 \% \\
\text { of initial users increased their use. }\end{array}$ \\
\hline$\overline{-13]}$ & $\begin{array}{l}\text { California } \\
\text { (USA) }\end{array}$ & Survey $[\mathrm{n}=1975]$ & Ride-hailing among millennials and Generation $X$ people & $\begin{array}{l}\text { 1. Limiting factors: preference for personal vehicle and safety. } \\
\text { 2. Those with higher value of time, higher use. } \\
\text { 3. Lower use in suburban/low density areas. }\end{array}$ \\
\hline $\begin{array}{l}\text { DIDI } \\
{[19]}\end{array}$ & China & Survey $[\mathrm{n}=9762]$ & $\begin{array}{l}\text { Ride-hailing (taxis and private car companies) and car-pooling } \\
\text { ("hitching service") service in operation. }\end{array}$ & $\begin{array}{l}\text { 1. The service is cheap and attracts travelers of green modes. } \\
\text { 2. Common reason for use: time savings. } \\
\text { 3. Common reasons for drivers: car and parking limitations. }\end{array}$ \\
\hline $\begin{array}{c}\text { Touring } \\
{[16]}\end{array}$ & $\begin{array}{c}\text { Ghent } \\
\text { (Belgium) }\end{array}$ & Pilot $[\mathrm{n}=90,2.5$ months $]$ & $\begin{array}{l}\text { Budget given to use several travel modes. Payment platform, not } \\
\text { for all modes. }\end{array}$ & $\begin{array}{l}\text { Clear reduction in car use (overall for daily commuting). Largely } \\
\text { substituted by privately owned e-bike. }\end{array}$ \\
\hline $\begin{array}{c}\text { CMaaS } \\
{[20]}\end{array}$ & (Sweden) & Pilot [n = 400, 6 months $]$ & $\begin{array}{l}\text { MaaS for a large company. Multimodal services and booking } \\
\text { platform exclusively for employees. }\end{array}$ & $\begin{array}{l}50 \% \text { of users are willing to use car-sharing. Possible shift from car } \\
\text { if good incentives are provided. }\end{array}$ \\
\hline $\begin{array}{c}\text { Tripi } \\
{[7]}\end{array}$ & $\begin{array}{l}\text { Sydney } \\
\text { (Australia) }\end{array}$ & Pilot $[\mathrm{n}=92,4$ months] & $\begin{array}{l}\text { Payment platform and three different multimodal monthly passes } \\
\text { (PT, Uber, taxi, car share, car rental). }\end{array}$ & $\begin{array}{l}\text { Financial benefits are key. "Pay-as-you-go + payment platform" is } \\
\text { not interesting. Multimodal monthly passes, reduced car use. }\end{array}$ \\
\hline $\begin{array}{l}\text { DriveNow } \\
\quad[15]\end{array}$ & $\begin{array}{l}\text { Copenhagen } \\
\text { (Denmark) }\end{array}$ & Survey $[\mathrm{n}=1496,2.5$ years $]$ & Free-floating car-sharing service, in operation since 2015. & $\begin{array}{l}\text { No evidence that membership minimized car ownership. } \\
48 \% \text { of trips would have been made by public transport }\end{array}$ \\
\hline
\end{tabular}


The Touring study was conducted with car users willing to reduce usage, and reported a clear reduction, especially in commuting; car use was largely replaced by private electric bicycles. In the case of Tripi, in the fourth (and last) month of the test, users who chose the pay-as-you-go model drove an average of $658 \mathrm{~km}$, while those who chose the "Green pass" (unlimited travel on public transport) drove only $222 \mathrm{~km}$. According to one study [7] the economic benefits are key and the pay-as-you-go + payment platform mix is not attractive to users.

DIDI, the large Chinese ride-sharing service, is priced similarly to the bus and is used by all socio-economic classes. It attracts users from all sustainable modes because of price and time savings, which is the advantage most recognized by its users. Of respondents, $12.5 \%$ use DIDI instead of their own car due to car use limitations and parking problems in their cities [19].

Alemi [13] surveyed youth and Generation X people in California about ride-hailing services and found that preference for personal vehicle use and safety concerns are the limiting factors for use. In terms of land use, the lowest number of services occur in suburban and low-density areas. Millennials, the better educated and those with a high time value are likely to use ridesharing.

Sixty four percent of DriveNow trips would have been made by active modes and mostly by public transport. Infrequent drivers considered DriveNow to be maintenancefree and cheaper than a private car. Frequent drivers used DriveNow for leisure trips and preferred to drive themselves rather than use a cab. Relocation of residence, changes in employment and household composition could lead to increased private car use [15].

\subsection{Mobility Apps Fostering Sustainable Mobility}

This section highlights key points from the articles selected on the persuasion strategies in mobility apps to promote sustainable urban travel modes.

Many voluntary travel behavior change (VTBC) interventions have been applied for over 20 years, mainly in western countries. Compared with mass communication, interventions that gave the individual information on their specific travel behavior proved to be more effective [6,34]. With advances in mobile technology, mobile phones have clearly become useful for implementing persuasion strategies [35], especially in the field of research.

Persuasive technology is widely described as technology that uses persuasion and social influence rather than coercion to modify users' attitudes or behaviors. Figure 6 shows the persuasive strategies studied in the last two decades, according to the frequency of times they have been addressed in scientific papers. The most studied are self-monitoring, feedback, gamification and rewards; cooperation, reduction, tunneling, framing and simulation are the least studied [6]. 
Tailoring

\section{Rewards}

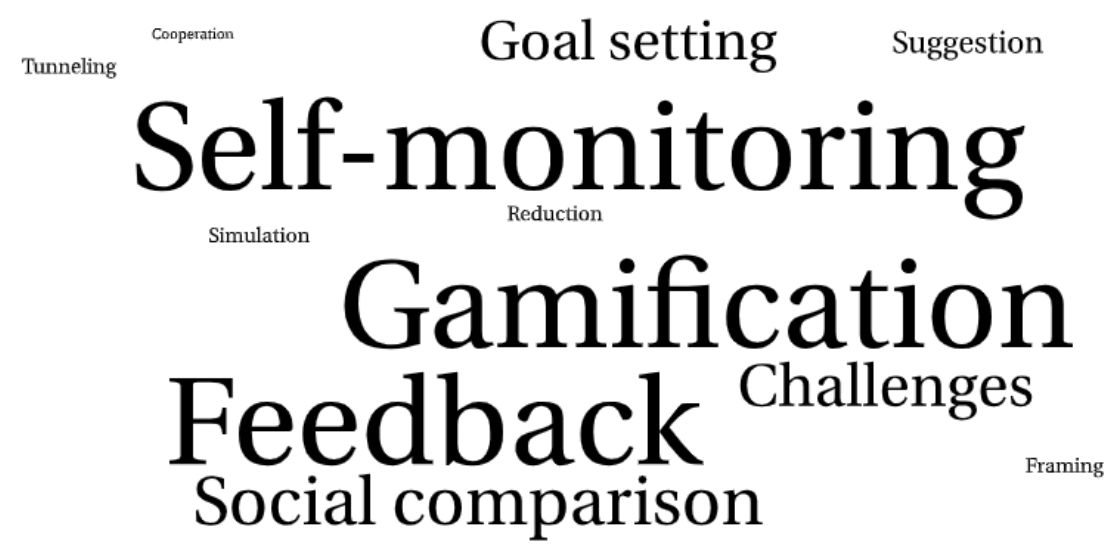

Figure 6. Word cloud with persuasion strategies.

Impact Assessment of Mobility Apps That Foster Sustainable Travel Behavior

The scientific review conducted by Anagnostopoulou [6] of persuasion systems between 2003 and 2018 estimates that 65\% have been successful, due to changes in the user's attitude or travel behavior, or satisfaction with the system or approach. However, only a few studies specifically evaluate behavior change, and most only test a short period of time (less than one month), which is insufficient to induce change.

This document extended the scientific review on persuasion systems to 2021 (Appendix B). A total of 42 articles were identified and, of those, only six met the following three requirements: (i) being an existing system or a pilot; (ii) having more than 50 participants; and (iii) lasting at least three months. Table 2 lists the characteristics of the six schemes that met these criteria.

Their duration in all those six cases ranged from three months (From5To4, StreetLife and Bellidea) to one year (GoEco!). The study with the fewest participants had 52 people (GoEco!) and the study with the most had 3400 (Routecoach). All of them were conducted in Europe. The six systems were carried out as prototypes, in most cases by universities, except for the From5to4 system, which was implemented by five entities, public companies and consulting firms, with no university participation. This system has been implemented in 30 different organizations, both public and private.

\section{- Website/app format}

In the case of Routecoach, the app acted as a "routing hub" to collect trip information, and could be used as a multimodal route planner, while the website was used for everything else: initial registration and filling out a survey to be recognized in an attitudinal profile, entering data of interest (important locations, usual routes, purposes of the trips made, displaying trip statistics). The website in the BetterPoints system appears to be used only to display a leaderboard with the points obtained in the challenges, which can also be viewed in the app. 
Table 2. Pilot apps and webs tested by a period of more than three months.

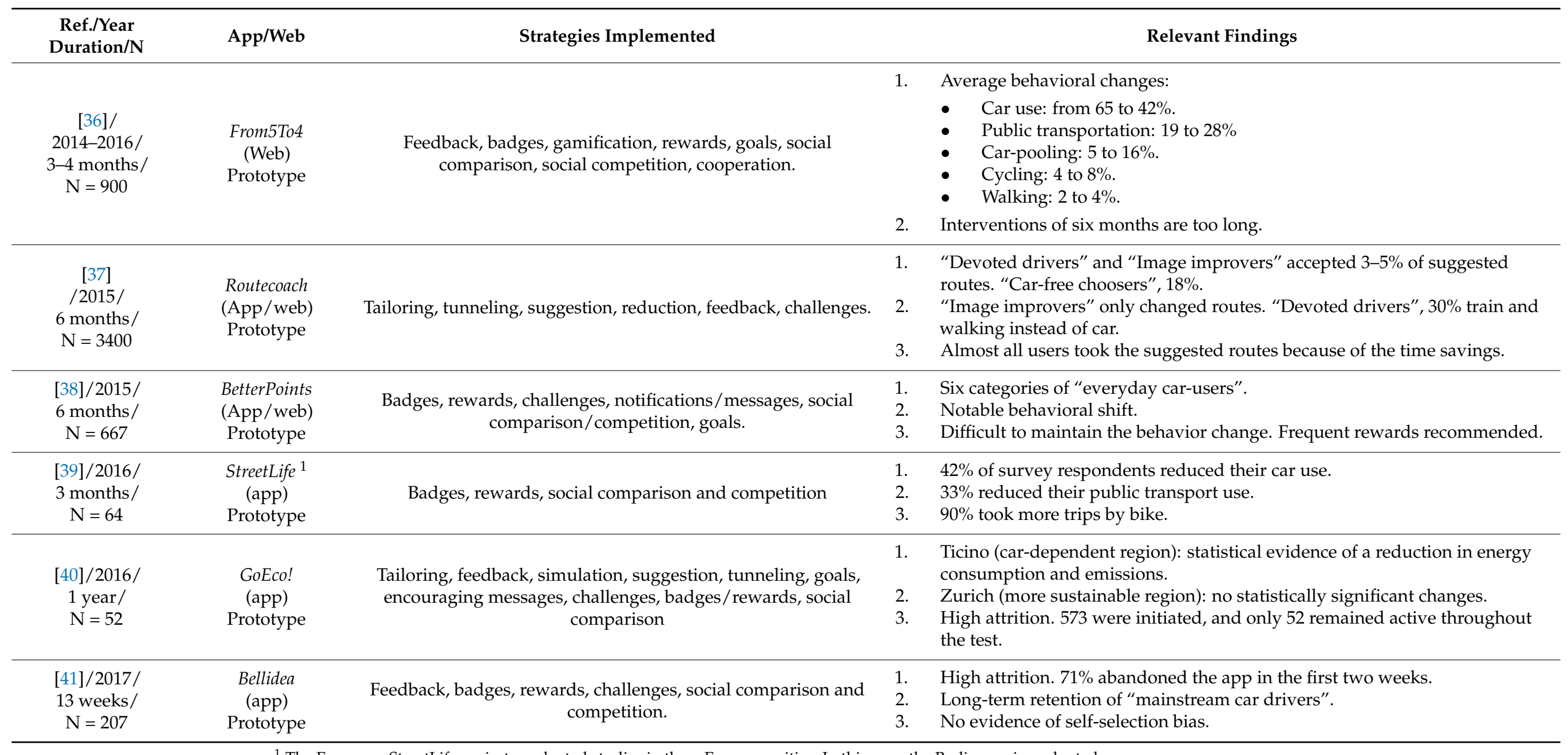

${ }^{1}$ The European StreetLife project conducted studies in three European cities. In this case, the Berlin app is evaluated. 


\section{- $\quad$ Type of tracking}

Four of the systems studied in Table 2 automatically tracked user trips (Routecoach, Streetlife, GoEco! and Bellidea), while the other two systems required users to manually track their trips (From5to4, Betterpoints). Automatic tracking through apps is not yet effective. In the case of Bellidea, the algorithm achieved $87 \%$ accuracy in estimating the route, and performed self-learning with manual validation by users. In the case of From5to4 (manual tracking), users needed only one minute per day to record their travel behavior (travel modes and distances).

There are two differences worth noting between the methods of the experiments: (1) only in the GoEco! Experiment was the sample divided into two subgroups for including a control group; and (2) the Routecoach system experiment included a pre-intervention segmentation of users based on the Segment project model [42] to classify travelers into eight categories according to their attitudes towards sustainability.

\section{- Persuasive strategies}

The most commonly repeated strategies in the six studies in Table 2 are badges, rewards, challenges, social comparison, feedback and social competition, which are used in at least four of the studies in the table. This is similar to the findings of another study [6], except that: (i) challenges and social comparison appear more frequently in these studies; (ii) social competition is not considered by Anagnostopoulou [6], and can be differentiated by simply comparing users, or establishing a competition.

Rewards can be in the form of points for traveling in sustainable modes (From5to4, BetterPoints, StreetLife), to achieve goals that are proposed to the user in the form of challenges (From5to4), for logging trips made on the app/web (BetterPoints). Rewards can be in the form of prizes for highly sustainable travel behaviors ("Bike Award", From5to4), to redeem points for money (discounts in local stores, BetterPoints), or for planting trees in the participant's city (StreetLife) or for equipment to travel properly by sustainable means of transport (bicycle helmets, StreetLife). Social comparison can be done through a leaderboard of participants (From5to4, Routecoach, BetterPoints). In the case of challenges, users can propose challenges to other participants (Routecoach).

\section{- $\quad$ Travel behavior impacts}

There is a notable change in behavior with the From5to4 system, with a large reduction in car use and a significant increase in sustainable modes, mainly car-pooling. As previously mentioned, in this case the travel behavior was tracked manually by each user and the validation was done by the captain of each team.

Only self-proclaimed "everyday car users" were studied in the BetterPoints system. The change in travel behavior was also significant: $81 \%$ of the trips recorded were carsubstituted trips. It is important to note that only $12 \%$ (called "maintainers") maintained their activity over the six months, and so reduced their car use.

The Segment project user categorization [42] was used in the Routecoach system. Users whose profile was most closely related to the use of private vehicles, "devoted drivers" and "image improvers", were observed to accept from 3 to $5 \%$ of all the routes suggested by the system.

The persuasive strategies in the StreetLife system, tested in Berlin, were geared towards promoting cycling. The results obtained through surveys at the end of the experiment were positive. Of the users who reported a change in behavior influenced by the app, $90 \%$ increased their use of bicycles, and $42 \%$ and $33 \%$ reduced their use of cars and public transport respectively. A model (called TAPAS) was used to estimate what the impacts would have been in the whole of Berlin. Daily pollution could have been reduced from 5.64 tons of $\mathrm{CO}_{2}$ to 5.41. In comparison with the Berlin population, the number of students was over-represented and the older cohort was under-represented. 
GoEco! was tested in the canton of Ticino (74\% of car and motorcycle kilometers traveled) and in the city of Zurich (less, with 57\%). The mobility of all trips and of the most frequent ones ("systematic routes") was studied. The app was not found to lead to statistically significant changes in the systematic routes, but only in the case of Ticino. The treatment group emitted $31 \%$ less $\mathrm{CO}_{2}$ per kilometer than the control group on the systematic routes. In the case of Zurich, there was a decrease but it was not statistically significant. The authors considered that Ticino had ample room for improvement compared with Zurich. It should be noted that the sample was small.

\section{- Attrition/App churn}

In four of the six studies, serious attrition or app churn problems were recognized. In the case of From5to4, which is web-based, it was designed as a six-month intervention; however, for some participating organizations this was too long. In the case of RouteCoach, only $15 \%$ of users responded to the initial survey and recorded the majority of trips. In the case of BetterPoints, only $12 \%$ of participants maintained significant activity until the end. $37 \%$ percent of those who downloaded the app reported no activity or stopped after the first month. In the case of GoEco!, only 52 users (573 started) finished. It should be taken into account that this intervention lasted one year. In the case of Bellidea, $71 \%$ dropped out in the first two weeks.

\section{Discussion}

Sociodemographic factors are good predictors of the adoption of new mobility services [13]. Young adults are more willing to adopt these emerging services [8] and are more accustomed to using apps [16]. Economic constraints also make them more likely to use shared modes, which are cheaper than traditional ones such as car ownership. Older people are starting to use these new services more, and smartphone use is spreading to the older population. In general, the use of new mobility services by men is much higher [15], so urban travel apps can be designed to consider three different target populations: (i) people who use more new mobility services through apps, namely young people and older adults interested in technology; (ii) older adults not much interested in technology; and (iii) women.

A key factor for modal shift is whether the traveler is financially constrained. In MaaS tests, multimodal subscription packages with economic advantages are more attractive [7]. In the case of UbiGo, some drivers wanted to test whether it was cheaper than using their own car [17], and some users claim that car-sharing is cheaper than their own car [15]. More affluent drivers are less likely to use Park and Ride [18]. Wealthier bus users in China are unlikely to use ride-hailing through DIDI even though it is similarly priced [19]. Travelers who are not financially constrained are more likely to be interested in non-financial benefits. This points to two conclusions: (i) apps should offer customization; and (ii) for less wealthy travelers, apps must show the price of services in a very visible way as it severely affects their mode choices.

Providing reliable and real-time information is a key demand of today's users, especially young travelers who are very sensitive to their time being wasted [8]. Real-time information enables significant reductions in travel time, estimated at $15 \%$ by Song [23] for travel by public transport and at $5-10 \%$ by $\mathrm{Li}$ [21] for private cars. This allows the user to choose the fastest route and start at the optimal time, in addition to increasing the perception of safety at public transport stops, when they are "unsavory", or when waiting at night, mainly in the case of women [22]. A significant percentage of users consider it appropriate to share information with one another in order to have more knowledge of the level of service (crowding, traffic jams, etc.). The operator's information is sometimes not up to date, so it would be beneficial for apps to allow users to provide updated information. Recent studies reveal that the use of public transport apps has increased the number of users by up to $30 \%$ [22].

Most studies show that users prefer multimodal subscription packages rather than pay-as-you-go [8]. A major advantage of subscription packages is that they require the 
user to consider carefully how they want to travel in the next month/s and to explore the transport system, know their personal interests and probably travel more efficiently due to a greater knowledge of the consequences of each travel mode [17]. Some authors propose that the highest level of MaaS integration should include ticketing, payment, integration of all modes via ICT (basically, a digital single platform) and offering subscription packages $[43,44]$.

Subscription packages are a way of putting customization into practice. Customization offers economically affordable access to modes of transport for people with reduced mobility, elderly people and people with financial constraints. In the case of older people who no longer drive, the use of ride-hailing a few times a month enables them to take care of business or visit relatives [28], and people unable to afford a car can access car-sharing for a limited number of times a month. In addition, if transportation services operate together under the same system, they may be more affordable economically. Cabs could become a feasible alternative for people with reduced mobility [44].

Recent studies suggest that travelers want to include free unlimited travel on public transport in subscription packages $[7,12]$ and prefer a simple package with two or three modes [7].

One of the highlights of UbiGo was an efficient customer service, with a mobility broker that acted as a mediator between service providers and users, leading to high participant satisfaction. This agent may make it easier to attract older people to the service [17]. Comparisons are also often made between transport subscription packages and those of Netflix or internet-television-mobile. Netflix is a leisure service and only costs a few euros per month, making it very different from transport, which is a vital activity that has a much higher economic cost. Moreover, transport supply is complex and difficult for users to understand sufficiently. A traveler must consider many more variables than when choosing a Netflix or internet-telephone-television package, and citizens have not generally experienced all modes of transport. For all these reasons, transport packages require customer service.

Many public transport services do not have enough interaction with users to gain an idea of their opinion. This gap can be narrowed by allowing (i) the option of rating services, like Uber [32]; and (ii) a section for users to share feedback with one another [12].

The MaaS pilots that offered multimodal subscription packages (UbiGo, UMAJI, MenGo and Tripi) were successful in reducing car use, and all were characterized by a clear sustainability orientation $[7,17,33]$. To ensure a sustainability-based approach, the public administration must monitor the services offered [44].

The results for ride-hailing and car-sharing services reveal both positive and negative aspects. They reduce the use of the private vehicle and allow easy and cheap access to a car for people who do not want to buy one. For some regular drivers, car-sharing works as an alternative to taxi/ride-hailing because they prefer to drive. One reason for not using ride-hailing is safety/security. However, the results indicate that a significant percentage of ride-hailing or car-sharing trips would have been made in more sustainable ways if they did not exist [15,19]. A substantial group uses ride-hailing services because they value personal time highly. However, in terms of sustainability, ride-sharing (e.g., Uber, Pool) rather than ride-hailing should be encouraged [13].

The persuasion programs implemented through apps and websites offered encouraging results as a means of reducing car use. Only programs lasting at least three months were evaluated. Unlike the apps related to MaaS, whose main focus is to satisfy the user, the greatest problem with this type of program is abandonment during the intervention. The benefits are not that attractive to users, as they primarily concern personal health and the environment in addition to reducing travel time.

The most used app/web features were travel behavior feedback; badges, such as points for traveling in sustainable modes; virtual rewards for sustainable behavior or real rewards, such as redeeming points earned for discounts in stores; sustainability-oriented 
challenges; and social comparison and competition, such as a leaderboard with the points obtained by each user.

A large number of participants in app-based persuasive interventions lose motivation at the beginning. On the one hand, app churn is a recognized phenomenon, characterized by stopping using a smartphone app one month after downloading it; some studies estimate that $60 \%$ of users do so [38]. On the other hand, participants in behavior change programs suffer attrition, leading many to drop out. Participants in these programs are volunteers, so there is nothing to hold them back if they want to drop out [40]. However, in the case of From5to4 the average user activity was high. The operation was not by individuals but by groups. The interventions were carried out in companies, and the groups were made up of employees who were co-workers. In each group, one member had to take on the role of "captain" and ensure that all members recorded their trips correctly on the web platform. The reason for the effective engagement of From 5 to 4 users was likely group operation.

Apps interact with the user, but they need to engage less active users by introducing challenges, goals, rewards, social competitions, motivational notifications and feedback more frequently. Some participants only showed activity when they found special motivation. For example, the BetterPoints data showed a significant increase in activity during weeks 17-18, probably due to the existence of competition with rewards [38]. In addition, users demand social networking features, to generate more interaction with each other. Tangible rewards or monetary feedback for those users who highly value monetary savings could improve app engagement $[38,40]$. The ability to redeem points for in-store purchases could be very attractive for those who like to spend leisure time shopping $[38,45]$.

Users who pay for the subscription are more willing to use the app because they pay for it. The few published studies on MaaS with multimodal subscription packages show widespread use by subscribers. These results demonstrate a "loyalty" of subscribers, as has been assumed by other authors [33]. Assuming this advantage of subscriptions, it is likely that persuasion-based mobility apps offering multimodal subscription packages would reduce the habitual attrition of their users.

According to Storme [16], pilot studies on MaaS are scarce due to the high economic and time cost. This leads to studies being experimental in shape and with biased and small samples. In addition, it is necessary to analyze the mobility data of MaaS providers, whether private or public companies. However, private companies do not seem to be willing to collaborate [44]. Joint projects between the university, the public administration and private companies are necessary.

According to Hensher, the travel behavior impacts of using mobility apps should be measured through digital devices (smartphone GPS). Information obtained through surveys is necessary (satisfaction, attitudes, beliefs, etc.), but is not accurate enough to measure changes in modal split [7].

One of the main reasons why the smartphone is a promising tool for changing the behavior of travelers is its ability to reach so many people around the world. However, studies on persuasion-based mobility apps/websites focused on demonstrating their effectiveness as a persuasion tool, and still have major limitations for reaching any solid conclusions.

As for studies of persuasion-based mobility systems, they have been carried out with small samples, mainly with young people and volunteers who tend to be environmentally conscious; financial incentives are often offered, and the experiments are spread over too short a period of time. The smartphone raised the hope that it could serve as a tool to reach many people, and this needs to be demonstrated. Similar to the MaaS studies, it must transcend the university environment, collaborating in this case with the entities responsible for existing apps that are already used throughout society.

Although urban mobility apps can promote sustainable travel habits, the following premises must first be met: (i) there must be a multimodal transportation supply, reliable and accessible for the most disadvantaged social groups [6]; and (ii) urban areas must be suitable for sustainable mobility, based on smart planning — avoiding urban sprawl-and on infrastructure that encourages active modes of travel [46]. 


\section{Conclusions}

The literature review of urban travel apps to improve mobility identified two key aspects: (i) the elements that apps must include to convince users to make more sustainable trips; and (ii) what makes an app attractive to travelers. It therefore combines two different areas: MaaS/new mobility services and persuasive technologies.

We searched Web of Science, Scopus and Google Scholar and selected a total of 297 scientific publications. Among them, special attention was paid to empirical studies, both on existing apps and in pilot studies with prototypes. For persuasive interventions, out of 42 papers on the use of apps/websites, we selected the six that have been used by more than 50 participants for at least three months. Only six scientific publications with pilot tests were identified in MaaS studies.

- Analysis of user-centered apps for mobility services

The MaaS schemes evaluated show positive preliminary results. Multimodal monthly passes could reduce car use by one third compared with pay-as-you-go systems [7]. However, it appears to take time to achieve significant reductions in car use [16].

It has been demonstrated that increased accessibility to transport services may lead to greater demand. The affordable cost of the DIDI ride-hailing service in China has attracted $37 \%$ of users who previously used public transportation [19].

Real-time information could provide significant reductions in travel time; one study estimated travel time reductions of up to $15 \%$ for public transport [23]. It also increases the perception of safety, especially at night and at "unsavory" stops. All this increases satisfaction with the transport service and generates a virtuous circle that attracts more trips. Recent studies suggest that the use of public transport apps increased the number of users by up to $30 \%$ [22].

The information provided by the operator could be reinforced if the platform allows users to report problems and incidences in the service [25] and offers users up-to-date information in real time [27].

- Changes in mobility behavior reported in pilot case studies with persuasive mobility apps:

The experiences in the evaluated persuasive apps were badges, rewards, challenging users to reach sustainability goals, social comparison and competition for prizes and travel patterns feedback.

The results for car use reduction appear encouraging. For example, $81 \%$ of the trips registered in the BetterPoints system were car-substituted trips [38]. In the case of From5to4, car use was reduced from $65 \%$ to $42 \%$ of the modal share [36].

The "app-churn" phenomenon is of great importance. Many participants download the app then engage in very little or no activity $[38,41]$. Urban travel apps compete with a multitude of apps from other sectors, as well as from their own sector. App persuasion strategies (feedback, challenges, goals, etc.) must appear more frequently to maintain app usage. In the case of the From5to4 persuasive system it worked successfully. The reason may be social, because the use of the app was in a group, and among co-workers [47].

One key aspect is the design of urban travel apps that have attractive elements for the user (multimodal monthly passes, real-time information, etc.) and include persuasive elements. Synergies between these two elements-customized design and challenging tools - can increase the share of sustainable modes.

Published studies of MaaS with multimodal subscription packages show extensive subscriber usage $[7,17,33]$. A persuasive-based mobility app may offer multimodal subscription packages to increase the number of users over time.

In most of the pilot studies evaluated, modal shift impacts are measured by selfreported surveys rather than by GPS tracking of user trips. This could produce a bias in the changes reported. GPS-based tools are 80-90\% accurate, but they are still underdeveloped [41]. Smartphones are recognized as a promising tool to encourage sustainable habits, involving a large number of users, but it is yet to be studied. 
All in all, the experiences documented show that soft measures alone are not enough to achieve drastic reductions in car use. It is therefore necessary to find a way to complement them with clear restrictions for less sustainable modes, in a traditional "carrot and stick" combination.

Funding: This scientific work has been developed within the framework of the national R\&D project called U-MOVE (acronym of "smart strategies for Urban sustainable MObility: role of traVEl apps"), funded by the Spanish Ministry of Science and Innovation (project reference:PID2019-104273RB-100). Daniel Casquero is also grateful for his research grant funded by the Spanish Ministry of Science and Innovation and the European Social Fund (Grant: PRE2020-096124).

Institutional Review Board Statement: Not applicable.

Informed Consent Statement: Not applicable.

Data Availability Statement: Not applicable.

Conflicts of Interest: The authors declare no conflict of interest.

\section{Appendix A}

Table A1. Empirical studies on urban travel apps.

\begin{tabular}{|c|c|c|c|c|}
\hline Ref. & Authors (Year) & App & Method & Location \\
\hline [17] & Sochor et al. (2015) & UbiGo & $\begin{array}{c}\text { Pilot } \\
{[\mathrm{n}=195,6 \text { months }]}\end{array}$ & Gothenburg (Sweden) \\
\hline [48] & Bopp et al. (2016) & $\begin{array}{l}\text { Active } \\
\text { Lions }\end{array}$ & Survey [n = 999] & Pennsylvania (USA) \\
\hline [29] & Xu et al. (2016) & - & Survey [n = 2043] & Switzerland \\
\hline [9] & Karlsson et al. (2017) & Smile & Pilot $[n=200,1$ year $]$ & Vienna (Austria) \\
\hline [18] & Gan \& Ye (2018) & - & Survey [n = 181] & Shanghai (China) \\
\hline [28] & Mulley et al. (2018) & - & 5 In-depth interviews & Sidney (Australia) \\
\hline [27] & Sarker et al. (2019) & - & Survey [n = 1369] & Copenhagen (Denmark) and Innsbruck (Austria) \\
\hline [31] & Dastjerdi et al. (2019) & - & Survey $[\mathrm{n}=828]$ & $\begin{array}{l}\text { Copenhagen } \\
\text { (Denmark) }\end{array}$ \\
\hline \multirow{2}{*}{ [33] } & \multirow{2}{*}{ Chang et al. (2019) } & UMAJI & Operational & Taipei (Taiwan) \\
\hline & & MenGo & Operational & Kaohsiung (Taiwan) \\
\hline [13] & Alemi et al. (2019) & - & Survey [n = 1975] & California (USA) \\
\hline [25] & Romero et al. (2020) & HARMONY & Pilot [n = 17, 1 week] & Madrid (Spain) \\
\hline [19] & Tang et al. (2020) & DIDI & Survey [n = 9762] & China (10 main cities) \\
\hline [12] & Caiati et al. (2020) & - & Survey $[\mathrm{n}=1078]$ & Amsterdam and Eindhoven (The Netherlands) \\
\hline [16] & Storme et al. (2020) & Touring & Pilot $[\mathrm{n}=90,2.5$ months $]$ & Ghent (Belgium) \\
\hline [20] & X. Zhao et al. (2020) & - & Pilot $[\mathrm{n}=400,6$ months $]$ & $\begin{array}{l}\text { Exclusive for a big company, 15,000 employees } \\
\text { (Sweden) }\end{array}$ \\
\hline [8] & $\begin{array}{l}\text { López- Carreiro et al. } \\
\text { (2020) }\end{array}$ & - & Focus groups & Madrid (Spain) \\
\hline [49] & Schikofsky et al., (2020) & - & Survey [n = 1067] & Germany \\
\hline [50] & Vij et al. (2020) & - & Survey [n = 3985] & Melbourne, Canberra, Sydney (Australia) \\
\hline [7] & Hensher et al. (2021) & Tripi & Pilot [n = 92, 4 months] & Sydney (Australia) \\
\hline [21] & Li et al. (2021) & Metropia & Operational [n = 380] & Austin (USA) \\
\hline [51] & Sun \& Wandelt (2021) & Baidu & Operational & China \\
\hline [15] & Haustein (2021) & DriveNow & $\begin{array}{l}\text { Operational. Survey } \\
{[\mathrm{n}=1496,2.5 \text { years }]}\end{array}$ & Copenhagen (Denmark) \\
\hline
\end{tabular}




\section{Appendix B}

Table A2. App and web based persuasive systems for encouraging sustainable mobility.

\begin{tabular}{|c|c|c|c|c|}
\hline Ref. & Authors (Year) & App or Web (Year) & Duration (Weeks) & Participants \\
\hline [52] & Broll et al. (2012) & TRIPZOOM (2003) & \multicolumn{2}{|c|}{ App design } \\
\hline [53] & Reitberger et al. (2007) & PerCues (2007) & \multicolumn{2}{|c|}{ App design and survey } \\
\hline [54] & Froehlich et al. (2009) & UbiGreen (2009) & 3 & 14 \\
\hline [55] & Takayama et al. (2009) & Ecoisland (2009) & 4 & 20 \\
\hline [56] & Harries et al. (2013) & bActive (2011) & 7 & 518 \\
\hline [57] & Jylhä et al. (2013) & Matkahupi (2013) & 4 & 12 \\
\hline [2] & Jariyasunant et al. (2012) & $Q T(2012)$ & 3 & 135 \\
\hline [58] & Gabrielli and Maimone (2013) & SUPERHUB (2013) & 4 & 8 \\
\hline [59] & Bothos et al. (2014) & Peacox $(2013)^{1}$ & 8 & 24 \\
\hline [60] & Meloni et al. (2014) & IPET (2014) & 2 & 15 \\
\hline [61] & Baird (2014) & Moves (2014) & 3 & 35 \\
\hline [36] & Buningh et al. (2016) & From5To4 (2014-2016) & $12-16$ & 900 \\
\hline [45] & Di Dio et al. (2018) & TrafficO2 (2014) & 4 & 77 \\
\hline [62] & Wunsch et al. (2016) & Frequent Biking Challenge (2014) & 2.5 & 29 \\
\hline [63] & Kazhamiakin et al. (2015) & Viaggia Roveretgoto (2015) & 5 & 40 \\
\hline [64] & Shankari et al. (2015) & E-Mission (2015) & 4 & 67 \\
\hline [65] & Schrammel et al. (2015) & Peacox $(2015)^{1}$ & 8 & 37 \\
\hline [37] & Semanjski et al. (2016) & Routecoach (2015) & 24 & 3400 \\
\hline [62] & Wunsch et al. (2016) & Bike to Work (2015) & 4 & 498 \\
\hline [38] & Bowden and Hellen (2018) & BetterPoints (2015) & 24 & 667 \\
\hline [66] & Meurer et al. (2016) & N.A. (2016) & 4 & 7 \\
\hline [67] & Ebermann and Brauer (2016) & N.A. (2016) & 3 & 248 \\
\hline [39] & Kelpin et al. (2016) & STREETLIFE (2016) & 12 & 64 \\
\hline [68] & Cheng and Lee (2015) & BikeTogether (N.A.) & 1 & 10 \\
\hline [69] & Piras et al. (2018) & IPET (2016) & 2 & 28 \\
\hline [70] & Huang et al. (2018) & SMART (2016) & 8 & 70 \\
\hline [40] & Cellina et al. (2019) & GoEco! (2016-2017) & 48 & 52 \\
\hline [71] & Khoshkangini et al. (2017) & N.A. (2017) & 9 & 110 \\
\hline [72] & Brazil et al. (2017) & Peacox $(2014)^{1}$ & 7 & 21 \\
\hline [73] & Park et al. (2017) & Ecotrips (2017) & 1 & 11 \\
\hline [41] & Cellina et al. (2021) & Bellidea (2017-2018) & 13 & 207 \\
\hline [74] & Wu et al. (2018) & GreenCommute (2018) & 1 & 11 \\
\hline [6] & Anagnostopoulou et al. (2018) & Optimum (2018) & 6 & 27 \\
\hline [75] & Campos-Sánchez et al. (2019) & Ciclogreen (2019) & 4 & 560 \\
\hline [76] & Ahmed et al. 2020) & SPARROWS (N.A.) & 4 & 52 \\
\hline
\end{tabular}

${ }^{1}$ The Peacox app was tested in Vienna and Dublin.

\section{References}

1. Shaheen, S.; Cohen, A.; Martin, E. Smartphone App Evolution and Early Understanding from a Multimodal App User Survey. In Disrupting Mobility; Springer: Cham, Swizerland, 2017; pp. 149-164. [CrossRef]

2. Jariyasunant, J.; Carrel, A.; Ekambaram, V.; Gaker, D.; Segupta, R.; Walker, J.L. The Quantified Traveler: Changing Transport Behavior with Personalized Travel Data Feedback; University of California Transportation Center: Berkeley, CA, USA, 2012.

3. Di Teulada, B.S.; Meloni, I. Individual Persuasive Eco-travel Technology, a mobile persuasive application for implementing voluntary travel behaviour change programmes. IET Intell. Transp. Syst. 2016, 10, 237-243. [CrossRef] 
4. Anagnostopoulou, E.; Bothos, E.; Magoutas, B.; Schrammel, J.; Mentzas, G. Persuasive Technologies for Sustainable Urban Mobility. 2016. Available online: http://arxiv.org/abs/1604.05957 (accessed on 2 July 2021).

5. Sunio, V.; Schmöcker, J.D. Can we promote sustainable travel behavior through mobile apps? Evaluation and review of evidence. Int. J. Sustain. Transp. 2017, 11, 553-566. [CrossRef]

6. Anagnostopoulou, E.; Bothos, E.; Magoutas, B.; Schrammel, J.; Mentzas, G. Persuasive technologies for sustainable mobility: State of the art and emerging trends. Sustainability 2018, 10, 2128. [CrossRef]

7. Hensher, D.A.; Ho, C.Q.; Reck, D.J. Mobility as a service and private car use: Evidence from the Sydney MaaS trial. Transp. Res. Part A Policy Pract. 2021, 145, 17-33. [CrossRef]

8. Lopez-Carreiro, I.; Monzon, A.; Lopez, E.; Lopez-Lambas, M.E. Urban mobility in the digital era: An exploration of travellers' expectations of MaaS mobile-technologies. Technol. Soc. 2020, 63, 101392. [CrossRef]

9. Karlsson, M.; Sochor, J.; Aapaoja, A.; Eckhardt, J.; König, D. Deliverable 4: Impact Assessment. MAASiFiE Project Funded by CEDR. 2017. Volume 35, Issue 4. Available online: https:/ / doi.org/10.1177/0193841x9401800105 (accessed on 8 July 2021).

10. Van Eck, N.J.; Waltman, L. Software survey: VOSviewer, a computer program for bibliometric mapping. Scientometrics 2010, 84, 523-538. [CrossRef]

11. Van Eck, N.J.; Waltman, L. \{VOSviewer\} Manual. Univeristeit Leiden. 2013. Available online: http://www.vosviewer.com/ documentation/Manual_VOSviewer_1.6.1.pdf (accessed on 12 June 2021).

12. Caiati, V.; Rasouli, S.; Timmermans, H. Bundling, pricing schemes and extra features preferences for mobility as a service: Sequential portfolio choice experiment. Transp. Res. Part A Policy Pract. 2020, 131, 123-148. [CrossRef]

13. Alemi, F.; Circella, G.; Mokhtarian, P.; Handy, S. What drives the use of ridehailing in California? Ordered probit models of the usage frequency of Uber and Lyft. Transp. Res. Part C Emerg. Technol. 2019, 102, 233-248. [CrossRef]

14. Kenyon, S.; Lyons, G. The value of integrated multimodal traveller information and its potential contribution to modal change. Transp. Res. Part F Traffic Psychol. Behav. 2003, 6, 1-21. [CrossRef]

15. Haustein, S. What role does free-floating car sharing play for changes in car ownership? Evidence from longitudinal survey data and population segments in Copenhagen. Travel Behav. Soc. 2021, 24, 181-194. [CrossRef]

16. Storme, T.; De Vos, J.; De Paepe, L.; Witlox, F. Limitations to the car-substitution effect of MaaS. Findings from a Belgian pilot study. Transp. Res. Part A Policy Pract. 2020, 131, 196-205. [CrossRef]

17. Sochor, J.; Strömberg, H.; Karlsson, I.C.M. Implementing mobility as a service: Challenges in integrating user, commercial, and societal perspectives. Transp. Res. Rec. 2015, 2536, 1-9. [CrossRef]

18. Gan, H.; Ye, X. Will commute drivers switch to park-and-ride under the influence of multimodal traveler information? A stated preference investigation. Transp. Res. Part F Traffic Psychol. Behav. 2018, 56, 354-361. [CrossRef]

19. Tang, B.J.; Li, X.Y.; Yu, B.; Wei, Y.M. How app-based ride-hailing services influence travel behavior: An empirical study from China. Int. J. Sustain. Transp. 2020, 14, 554-568. [CrossRef]

20. Zhao, X.; Vaddadi, B.; Sjöman, M.; Hesselgren, M.; Pernestål, A. Key barriers in MaaS development and implementation: Lessons learned from testing Corporate MaaS (CMaaS). Transp. Res. Interdiscip. Perspect. 2020, 8, 100227. [CrossRef]

21. Li, T.; Chen, P.; Tian, Y. Personalized incentive-based peak avoidance and drivers' travel time-savings. Transp. Policy 2021, 100, 68-80. [CrossRef]

22. Bian, J.; Li, W.; Zhong, S.; Lee, C.; Foster, M.; Ye, X. The end-user benefits of smartphone transit apps: A systematic literature review. Transp. Rev. 2021, 1-20. [CrossRef]

23. Song, C.; Guan, W.; Ma, J. Potential travel cost saving in urban public-transport networks using smartphone guidance. PLoS ONE 2018, 13, e0197181. [CrossRef] [PubMed]

24. Lyons, G.; Hammond, P.; Mackay, K. The importance of user perspective in the evolution of MaaS. Transp. Res. Part A Policy Pract. 2019, 121, 22-36. [CrossRef]

25. Romero, C.; Monzón, A.; Alonso, A.; Julio, R. Added value of a customized transit app for metropolitan bus trips. Transp. Res. Procedia 2020, 47, 513-520. [CrossRef]

26. Wessel, N.; Allen, J.; Farber, S. Constructing a routable retrospective transit timetable from a real-time vehicle location feed and GTFS. J. Transp. Geogr. 2017, 62, 92-97. [CrossRef]

27. Sarker, R.I.; Kaplan, S.; Anderson, M.K.; Haustein, S.; Mailer, M.; Timmermans, H.J.P. Obtaining transit information from users of a collaborative transit app: Platform-based and individual-related motivators. Transp. Res. Part C Emerg. Technol. 2019, 102, 173-188. [CrossRef]

28. Mulley, C.; Nelson, J.D.; Wright, S. Community transport meets mobility as a service: On the road to a new a flexible future. Res. Transp. Econ. 2018, 69, 583-591. [CrossRef]

29. Xu, R.; Frey, R.M.; Fleisch, E.; Ilic, A. Understanding the impact of personality traits on mobile app adoption-Insights from a large-scale field study. Comput. Hum. Behav. 2016, 62, 244-256. [CrossRef]

30. Karlsson, I.C.M.; Mukhtar-Landgren, D.; Smith, G.; Koglin, T.; Kronsell, A.; Lund, E.; Sarasini, S.; Sochor, J. Development and implementation of Mobility-as-a-Service-A qualitative study of barriers and enabling factors. Transp. Res. Part A Policy Pract. 2020, 131, 283-295. [CrossRef]

31. Mehdizadeh Dastjerdi, A.; Kaplan, S.; de Abreu e Silva, J.; Nielsen, O.A.; Pereira, F.C. Participating in environmental loyalty program with a real-time multimodal travel app: User needs, environmental and privacy motivators. Transp. Res. Part D Transp. Environ. 2019, 67, 223-243. [CrossRef] 
32. Jittrapirom, P.; Caiati, V.; Feneri, A.M.; Ebrahimigharehbaghi, S.; Alonso-González, M.J.; Narayan, J. Mobility as a service: A critical review of definitions, assessments of schemes, and key challenges. Urban Plan. 2017, 2, 13-25. [CrossRef]

33. Chang, S.K.J.; Chen, H.Y.; Chen, H.C. Mobility as a service policy planning, deployments and trials in Taiwan. IATSS Res. 2019, 43, 210-218. [CrossRef]

34. Gärling, T.; Bamberg, S.; Friman, M.; Fujii, S.; Richter, J. Implementation of Soft Transport Policy Measures to Reduce Private Car Use in Urban Areas. Geography 2008, 5, 1-12.

35. Gössling, S. ICT and transport behavior: A conceptual review. Int. J. Sustain. Transp. 2018, 12, 153-164. [CrossRef]

36. Buningh, S.; Venema, A.; Martijnse-Hartikka, R. MOBI-Promoting Smart Mobility to Employees. 2016. Available online: http: //www.mobi-project.eu/site/assets/files/1071/d1_3_mobi_final_report_-_results_and_lessons.pdf (accessed on 15 June 2021).

37. Semanjski, I.; Aguirre, A.J.L.; De Mol, J.; Gautama, S. Policy 2.0 platform for mobile sensing and incentivized targeted shifts in mobility behavior. Sensors 2016, 16, 1035. [CrossRef]

38. Bowden, H.; Hellen, G. A Data Driven, Segmentation Approach to Real World Travel Behaviour Change, Using Incentives and Gamification; Springer International Publishing: Berlin/Heidelberg, Germany, 2018; ISBN 9783319997568.

39. Kelpin, R.; Giesel, F.; Heinrichs, M. Streetlife Field Trials-Applied Gamification Approaches as a Key to More Sustainable Mobility Behaviour. In Proceedings of the European Transport Conference 2016, Barcelona, Spain, 5-7 October 2016.

40. Cellina, F.; Bucher, D.; Mangili, F.; Simão, J.V.; Rudel, R.; Raubal, M. A large scale, app-based behaviour change experiment persuading sustainable mobility patterns: Methods, results and lessons learnt. Sustainability 2019, 11, 2674. [CrossRef]

41. Cellina, F.; Vittucci Marzetti, G.; Gui, M. Self-selection and attrition biases in app-based persuasive technologies for mobility behavior change: Evidence from a Swiss case study. Comput. Hum. Behav. 2021, 125, 106970. [CrossRef]

42. Anable, J.; Wright, S. Work Package 7 Golden Questions and Social Marketing Guidance Report Authors: Dr. Jillian Anable and Dr. Steve Wright (University of Aberdeen) GOLDEN QUESTIONS REPORT. Intellegent Energy Europe. 2017. Available online: https://civitas.eu/sites/default/files/segment_deliverable_7.8.4_golden_questions_and_social_marketing_guidance_ report.pdf (accessed on 23 May 2021).

43. Kamargianni, M.; Li, W.; Matyas, M.; Schäfer, A. A Critical Review of New Mobility Services for Urban Transport. Transp. Res. Procedia 2016, 14, 3294-3303. [CrossRef]

44. Utriainen, R.; Pöllänen, M. Review on mobility as a service in scientific publications. Res. Transp. Bus. Manag. 2018, 27, 15-23. [CrossRef]

45. Di Dio, S.; La Gennusa, M.; Peri, G.; Rizzo, G.; Vinci, I. Involving people in the building up of smart and sustainable cities: How to influence commuters' behaviors through a mobile app game. Sustain. Cities Soc. 2018, 42, 325-336. [CrossRef]

46. Mouratidis, K.; Peters, S.; van Wee, B. Transportation technologies, sharing economy, and teleactivities: Implications for built environment and travel. Transp. Res. Part D Transp. Environ. 2021, 92, 102716. [CrossRef]

47. Buningh, S.; Martijnse-Hartikka, R.; Christiaens, J. Mobi-modal shift through gamification. In Proceedings of the Transport Research Arena (TRA) 5th Conference: Transport Solutions from Research to Deployment, Paris, France, 14-17 April 2014.

48. Bopp, M.; Sims, D.; Matthews, S.A.; Rovniak, L.S.; Poole, E.; Colgan, J. There's an app for that: Development of a smartphone app to promote active travel to a college campus. J. Transp. Health 2016, 3, 305-314. [CrossRef]

49. Schikofsky, J.; Dannewald, T.; Kowald, M. Exploring motivational mechanisms behind the intention to adopt mobility as a service (MaaS): Insights from Germany. Transp. Res. Part A Policy Pract. 2020, 131, 296-312. [CrossRef]

50. Vij, A.; Ryan, S.; Sampson, S.; Harris, S. Consumer Preferences for Mobility-as-a-Service (MaaS) in Australia. Transp. Res. Part C Emerg. Technol. 2020, 117, 102699. [CrossRef]

51. Sun, X.; Wandelt, S. Transportation mode choice behavior with recommender systems: A case study on Beijing. Transp. Res. Interdiscip. Perspect. 2021, 11, 100408. [CrossRef]

52. Broll, G.; Cao, H.; Ebben, P.; Holleis, P.; Jacobs, K.; Koolwaaij, J.; Luther, M.; Souville, B. Tripzoom: An app to improve your mobility behavior. In Proceedings of the 11th International Conference on Mobile and Ubiquitous Multimedia, Ulm, Germany, 4-6 December 2012; pp. 1-4. [CrossRef]

53. Reitberger, W.; Ploderer, B.; Obermair, C.; Tscheligi, M. The PerCues Framework and Its Application for Sustainable Mobility. In Proceedings of the Persuasive Technology; de Kort, Y., IJsselsteijn, W., Midden, C., Eggen, B., Fogg, B.J., Eds.; Springer: Berlin/Heidelberg, Germany, 2007; pp. 92-95.

54. Froehlich, J.; Dillahunt, T.; Klasnja, P.; Mankoff, J.; Consolvo, S.; Harrison, B.; Landay, J.A. UbiGreen: Investigating a Mobile Tool for Tracking and Supporting Green Transportation Habits. Sustainability 2009, 56, 1043-1052.

55. Takayama, C.; Lehdonvirta, V.; Shiraishi, M.; Washio, Y.; Kimura, H.; Nakajima, T. Ecoisland: A system for persuading users to reduce $\mathrm{CO}_{2}$ emissions. In Proceedings of the 2009 Software Technologies for Future Dependable Distributed Systems, Tokyo, Japan, 17 March 2009; pp. 59-63.

56. Harries, T.; Eslambolchilar, P.; Stride, C.; Rettie, R.; Walton, S. Walking in the wild-Using an always-on smartphone application to increase physical activity. In IFIP Conference on Human-Computer Interaction; Springer: Berlin/Heidelberg, Germany, 2013; pp. 19-36. [CrossRef]

57. Jylhä, A.; Nurmi, P.; Sirén, M.; Hemminki, S.; Jacucci, G. Matkahupi: A persuasive mobile application for sustainable mobility. In Proceedings of the 2013 ACM Conference on Pervasive and Ubiquitous Computing Adjunct Publication, Zurich, Switzerland, 8-12 September 2013; pp. 227-230. [CrossRef] 
58. Gabrielli, S.; Maimone, R. Digital interventions for sustainable urban mobility: A pilot study. In Proceedings of the 2013 ACM Conference on Pervasive and Ubiquitous Computing Adjunct Publication, Zurich, Switzerland, 8-12 September 2013; pp. 119-122. [CrossRef]

59. Bothos, E.; Mentzas, G.; Prost, S.; Schrammel, J.; Röderer, K. Watch your emissions: Persuasive strategies and choice architecture for sustainable decisions in urban mobility. Psychnol. J. 2014, 12, 107-126.

60. Meloni, I.; Sanjust, B.; Delogu, G.; Sottile, E. Development of a technological platform for implementing VTBC programs. Transp. Res. Procedia 2014, 3, 129-138. [CrossRef]

61. Baird, T. "Nudging" Active Travel: A Framework for Behavioral Interventions Using Mobile Technology. In Proceedings of the Transportation Research Board 93rd Annual Meeting, Washington, DC, USA, 12-16 January 2014.

62. Wunsch, M.; Millonig, A.; Seer, S.; Schechtner, K.; Stibe, A.; Chin, R.C.C. Challenged to Bike: Assessing the Potential Impact of Gamified Cycling Initiatives. Evaluation 2016, 23, 24.

63. Kazhamiakin, R.; Marconi, A.; Perillo, M.; Pistore, M.; Valetto, G.; Piras, L.; Avesani, F.; Perri, N. Using gamification to incentivize sustainable urban mobility. In Proceedings of the 2015 IEEE First International Smart Cities Conference (ISC2), Guadalajara, Mexico, 25-28 October 2015. [CrossRef]

64. Shankari, K.; Park, J.; Gadgil, T.; Katz, R.H.; Culler, D.E. Information Display for Societal Problems: Data, Game, or Choice? 2015. Available online: https:/ / www2.eecs.berkeley.edu/Pubs/TechRpts/2015/EECS-2015-7.pdf (accessed on 28 June 2021).

65. Schrammel, J.; Prost, S.; Mattheiss, E.; Bothos, E.; Tscheligi, M. Using Individual and Collaborative Challenges in Behavior Change Support Systems: Findings from a Two-Month Field Trial of a Trip Planner Application. In International Conference on Persuasive Technology; MacTavish, T., Basapur, S., Eds.; Springer International Publishing: Cham, Switzerland, 2015; Volume 9072, pp. 160-171.

66. Meurer, J.; Lawo, D.; Janßen, L.; Wulf, V. Designing mobility eco-feedback for elderly users. In Proceedings of the Proceedings of the 2016 CHI Conference Extended Abstracts on Human Factors in Computing Systems, San Jose, CA, USA, 7-12 May 2016; pp. 921-926.

67. Ebermann, C.; Brauer, B. The Role of Goal Frames Regarding the Impact of Gamified Persuasive Systems on Sustainable Mobility Behavior. Research Papers, 174. 2016. Available online: http:/ / aisel.aisnet.org/ecis2016_rp/174 (accessed on 10 July 2021).

68. Cheng, Y.-M.; Lee, C.-L. Persuasive and engaging design of a Smartphone App for cycle commuting. mUX J. Mob. User Exp. 2015, 4, 1. [CrossRef]

69. Piras, F.; Sottile, E.; Meloni, I. Modal Share Change following Implementation of Travel Demand Management Strategies. Transp. Res. Rec. 2018, 2672, 731-741. [CrossRef]

70. Huang, B.; Thomas, T.; Groenewolt, B.; Fioreze, T.; van Berkum, E. The effect of incentives to promote cycling: A mobility living lab. In Proceedings of the Proceedings of the Transportation Research Board 97th Annual Meeting, Washington, DC, USA, 7-11 January 2018.

71. Khoshkangini, R.; Valetto, G.; Marconi, A. Generating personalized challenges to enhance the persuasive power of gamification. CEUR Workshop Proc. 2017, 1833, 70-83.

72. Brazil, W.; Caulfield, B.; Bothos, E. An Examination of the Role of Emissions Information in Transport Behaviour: The Results of a Smart Phone Trial in Dublin, Ireland. In Proceedings of the 96th Annual Meeting of the Transportation Research Board, Washington, DC, USA, 8-12 January 2017; pp. 8-12.

73. Park, H.; Sanguinetti, A.; Castillo-Cortes, G. EcoTrips: Leveraging Co-benefits and Metaphorical Metrics in a Mobile App to Promote Walking and Biking for Short Trips. In Design, User Experience, and Usability: Designing Pleasurable Experiences; Springer: Berlin/Heidelberg, Germany, 2017; Available online: https:/ / escholarship.org/uc/item/4wc8g5sm (accessed on 1 July 2021).

74. Wu, S.; Bai, Q.; Sengvong, S. GreenCommute: An influence-aware persuasive recommendation approach for public-friendly commute options. J. Syst. Sci. Syst. Eng. 2018, 27, 250-264. [CrossRef]

75. Campos-Sánchez, F.S.; Valenzuela-Montes, L.M.; Abarca-Álvarez, F.J. Evidence of green areas, cycle infrastructure and attractive destinations working together in development on urban cycling. Sustainability 2019, 11, 4730. [CrossRef]

76. Ahmed, S.; Adnan, M.; Janssens, D.; Wets, G. A personalized mobility based intervention to promote pro-environmental travel behavior. Sustain. Cities Soc. 2020, 62, 102397. [CrossRef] 